\title{
Dose Response for UV-induced Immune Suppression in People of Color: Differences Based on Erythemal Reactivity Rather than Skin Pigmentation" $†$
}

\author{
MaryJane K. Selgrade, ${ }^{1}$ Marjo V. Smith, ${ }^{2}$ Lois J. Oberhelman-Bragg, ${ }^{3}$ Gordon J. LeVee, ${ }^{3}$ Hillel S. Koren ${ }^{1}$ \\ and Kevin D. Cooper ${ }^{\star 3,4}$ \\ ${ }^{1}$ National Health and Environmental Effects Research Laboratory, US EPA, Research Triangle Park, NC; \\ ${ }^{2}$ Analytical Sciences, Research Triangle Park, NC; \\ ${ }^{3}$ Department of Dermatology, University of Michigan, Ann Arbor, Ml and \\ ${ }^{4}$ Department of Dermatology, Case Western Reserve University, Cleveland, $\mathrm{OH}$
}

Received 7 November 2000; accepted 5 April 2001

\begin{abstract}
Ultraviolet radiation (UVR) is known to suppress immune responses in human subjects. The purpose of this study was to develop dose responses across a broad range of skin pigmentation in order to facilitate risk assessment. UVR was administered using FS 20 bulbs. Skin pigmentation and UVR sensitivity were evaluated using Fitzpatrick classifications, minimal erythemal dose (MED), slope of the erythemal dose response curve (sED), baseline pigmentation and tanning response. To assess immune responses dinitrochlorobenzene (DNCB) was applied to irradiated buttock skin $72 \mathrm{~h}$ after irradiation. Two weeks later DNCB was applied to the inside upper arm. Skin thickness was measured before and after challenge. Dose response was modeled (to obtain a regression line) for the entire group of 185 subjects. With the exception of SED none of the above-mentioned pigmentation indicators contributed significantly to variability around the regression line. Thus, differences in sensitivity for multiple skin types based on Fitzpatrick classification or MED were not observed. However, differences in immune sensitivity to UVR were detected between subjects with steep erythemal dose response curves and those with moderate or flat responses. For subjects with steep erythemal responses the dose calculated to suppress the immune response by $50 \%$ was $114 \mathrm{~mJ} / \mathrm{cm}^{2}$. This group included individuals with Fitzpatrick skin types I-V, MED for these subjects ranged from 30 to 80
\end{abstract}

IIPosted on the website on 18 April 2001.

*To whom correspondence should be addressed at: Department of Dermatology, Case Western Reserve University, University Hospitals of Clevland, 11100 Euclid Avenue, Cleveland, OH 44106, USA.

Disclaimer: The paper has been reviewed by the National Health and Environmental Effects Research Laboratory, US Environmental Protection Agency and approved for publication. Approval does not signify that the contents necessarily reflect the views and policies of the agency. Mention of trade names or commercial products does not constitute endorsement or recommendation for use.

(C) 2001 American Society for Photobiology 0031-8655/00 $\$ 5.00+0.00$ $\mathbf{m J} / \mathrm{cm}^{2}$. The $50 \%$ suppression dose for subjects with weak or no erythemal response could not be computed (the dose response was flat). This resistant group included subjects with skin types IV-VI and MED for these subjects ranged from 41 to $>105 \mathrm{~mJ} / \mathrm{cm}^{2}$. This study provides a human dose response for UVR suppression of contact sensitivity that will be useful in risk assessment. It is the first study to provide this information using the FS sun lamp and is the first study to include people of color. The SED appears to be a new variable for identifying sensitive subjects at risk of UVR-induced immune suppression.

\section{INTRODUCTION}

The immunosuppressive effects of ultraviolet radiation (UVR) $\ddagger$ were originally described in mice with respect to immune responses to UV-induced skin cancers $(1,2)$. Subsequently, UVR-induced suppression of responses to contact sensitizers $(3,4)$ and a variety of infectious agents were observed (5-9). Immunosuppression has now been demonstrated in both light- and dark-skinned human subjects (10-12). Recently, the dose response for UVR-induced suppression of contact hypersensitivity in human subjects exposed via a solar simulator was reported (13). However, this study was limited to Caucasian subjects. A dose response for people of color has not been previously determined. Dose response data are necessary in order to assess the risk of immunosuppression associated with increased UVR exposures projected to occur as a result of stratospheric ozone depletion (14).

Determining the relative sensitivity of population subsets based on the degree of skin pigmentation is important in defining the population at risk and also has implications on the types of adverse health effects (diseases) of concern. Following UV exposure the capacity to mount a primary im-

\$Abbreviations: CHS, contact hypersensitivity; DNCB, dinitrochlorobenzene; DPCP diphenylcyclopropenone; MED, minimal erythemal dose; MSLR, mixed skin lymphocyte response; sED, slope of the erythemal dose response curve; SSR, solar simulated radiation; UVB, ultraviolet radiation $\mathrm{B}$; UVR, ultraviolet radiation. 
Table 1. Spectral distribution of UV wavebands present in FS-20 source*

\begin{tabular}{lcc}
\hline & UV wave band $(\mathrm{nm})$ & Output $\%$ \\
\hline UVC & $250-278$ & 0.50 \\
UVB-II & $280-298$ & 13.07 \\
UVB-I & $300-318$ & 39.85 \\
UVA-II & $320-338$ & 30.14 \\
UVA-I & $340-400$ & 16.45 \\
\hline
\end{tabular}

*Output measurement at $2 \mathrm{~nm}$ intervals were normalized at their peak values; percent of UV for each wave band between 250 and $400 \mathrm{~nm}$ is shown.

mune response is transiently impaired (for about 2 weeks in mice) $(15,16)$; adverse health effects may occur during this period as a result of primary challenges to the skin immune system. In lightly pigmented individuals these challenges include recognition of early skin cancer transformed or initiated cells (17). The incidence of nonmelanoma skin cancer among darkly pigmented individuals is very low (18), presumably because pigmentation protects against tumor initiation (12). However, viral (e.g. Herpes viruses), fungal (e.g. Candida albicans), bacterial (e.g. Mycobacteria, Borrelia) and parasitic infections (e.g. Leishmania) also challenge the skin immune system. The resulting diseases could be enhanced in individuals exposed to UVR and may be of concern to both darkly pigmented and fair-skinned individuals depending on the effect that pigmentation has on the susceptibility to UVR-induced immune suppression. Similarly, UVR-induced immune suppression may impair the effectiveness of vaccines that are delivered via the skin and depend on the successful activation of $\mathrm{T}$ cell-mediated responses.

In this study we assessed the immune response to contact sensitizers, a sensitive and highly quantitative assay, in human subjects of different skin types with and without exposure to UVR. The purpose was to determine the relationship between ultraviolet radiation B (UVB) dose and degree of immune suppression in human subjects across a broad range of skin pigmentation. The UVB response was emphasized because risk assessment in this area centers on projected health impacts of increased UVB penetration to the earth's surface as a result of decreased stratospheric ozone.

\section{METHODS}

UVR dosimetry and exposure. To administer UVR a portable phototherapy device was utilized (Derma control, Frankfort, IL) containing six FS20 bulbs which emitted light at $0.25 \mathrm{~mW} / \mathrm{cm}^{2}$ at a 10 in. source-to-skin distance. The spectral distribution of the UV wavebands present in this source is shown in Table 1. An international light IL443 Phototherapy Radiometer w/SEE 1240 Detector/ UVB filter was used to measure the UVB irradiance and data are reported as the readout of this device in $\mathrm{mJ} / \mathrm{cm}^{2}$. The source was chosen to facilitate direct comparisons between effects in humans and mice (a very large database using this same light source is available for mice). Also, much of the spectral distribution for this source is in the range likely to be affected by the depletion of the stratospheric ozone.

Subject selection and determination of skin type. The protocol, advertisement and informed consent form were approved by the University of Michigan Institutional Review Board. Subjects were recruited between the ages of 18 and 62 years. Individuals who were pregnant or nursing, were on medication or had a history of chronic disease or recent significant sun or tanning booth exposure were excluded from the study.

Several methods were used to determine relative skin pigmentation. Initially, skin types were assessed based on standard skin typing which uses skin/eye color, race and subjective recall of their responses to sun exposure for classification $(19,20)$. Once recruited each subject was tested to determine the erythemal dose response using a template with eight $1.5 \mathrm{~cm}^{2}$ squares adhered to the left buttock. (All other areas were draped.) The dose of exposure to each square on the grid was controlled by exposure time. Fair-skinned subjects were exposed at $30 \mathrm{~s}$ intervals from 0.5 to $4 \mathrm{~min}(60 \mathrm{~mJ} /$ $\mathrm{cm}^{2}$ ). Dark-skin subjects were exposed at $1 \mathrm{~min}$ intervals from 1 to $8 \mathrm{~min}\left(120 \mathrm{~mJ} / \mathrm{cm}^{2}\right)$. Very dark-skinned individuals were exposed at $1 \mathrm{~min}$ intervals for $3-10 \mathrm{~min}\left(150 \mathrm{~mJ} / \mathrm{cm}^{2}\right)$. Erythema was assessed $24 \mathrm{~h}$ after exposure. The first square with even, visible erythema to the borders of the square was used to establish the minimal erythemal dose (MED). In addition to this relatively subjective assessment the erythemal dose response was determined more objectively using a Chroma Meter CR-300 (Minolta Corp, Ramsey, NJ) which converts all colors within the range of human perception into a common numerical code. Degree of redness is indicated by " a', where $\mathrm{a}=60$ indicates red and $\mathrm{a}=-60$ indicates green. " $\mathrm{L}$ ", indicates the degree of lightness, where $\mathrm{L}=0$ indicates black and $\mathrm{L}=100$ indicates white. Chroma meter readings were obtained for each of the eight exposure sites on the grid and the redness value was plotted against the dose of UV delivered. Each subject was assigned a number that reflected the slope of this erythemal dose response curve (sED). Subjects with a $\Delta$ in redness $\geq 2$ at two successive UV doses were assigned an SED of 1 ; if the slope was moderate ( $\Delta$ in redness at two successive UV doses 0.5-2.0), the SED assigned was 2 ; if the slope was flat $(\Delta$ in redness at two successive UV doses $<0.5$ ), the sED assigned was 3 . Examples of sED 1 and sED 2 are shown in Fig. 1. sED 3 was essentially a flat line. The chroma meter was also used to assess baseline pigmentation (buttock skin prior to UVR) and the pigmentary response to UV after 1 week.

Study population. The initial study population included 129 subjects. Tables 2 and 3 provide demographic information on these subjects. Subjects were group by skin type (Table 2) based on photosensitivity as determined by MED. This cohort contained only 20 individuals with MED of $30-37.5 \mathrm{~mJ} / \mathrm{cm}^{2}$. In order to increase the number of fair-skinned individuals in the study, data from an additional group of 56 subjects ( 33 males and 23 females) obtained in another nonconcurrent, but similarly randomized, study were included in some of the data analyses. Most of the UV-exposed subjects in this study had MED between 30 and $37.5 \mathrm{~mJ} / \mathrm{cm}^{2}$; six (three males and three females) had MED below this range (24-27 mJ/ $\mathrm{cm}^{2}$ ) and one male and one female had MED above this range (45$60 \mathrm{~mJ} / \mathrm{cm}^{2}$ ).

$U V$ exposure and chemical sensitization. Two to four weeks after MED testing, individuals within a given skin type (defined by MED) were prospectively randomized, stratifying for gender and assigned to a UV or control exposure group. UV exposures were 1.5, 2.5 or 4 MED. (From this point on exposure doses will be expressed in $\mathrm{mJ} / \mathrm{cm}^{2}$.) Because MED could not be readily determined for subjects with MED $>100$, randomly assigned fixed doses of UV were administered to this group $\left(120,180\right.$ and $\left.400 \mathrm{~mJ} / \mathrm{cm}^{2}\right)$. A single UV dose was administered to a $3 \times 4$ in. site on the left buttock. (All other areas were draped). Chroma meter readings were also done at 2 weeks to assess the tanning response for the various skin types. Subjects were sensitized with $0.062 \%$ dinitrochlorobenzene (DNCB) on the left buttock and $0.048 \%$ diphenylcyclopropenone (DPCP) (Aldrich Chemical Co., Inc., Milwaukee, WI) on the right buttock $72 \mathrm{~h}$ following the UV exposure as previously described (11). Control subjects were similarly sensitized. Female subjects were sensitized 7-21 days after the last menstrual period because sensitization during the 1-6 day time frame gave less than optimal DNCB immunizations in the control group (21).

Challenge and scoring of elicitation response. Two weeks after sensitization subjects were antigen challenged on unirradiated upper inner arms as previously described (11). Five Finn chambers containing acetone as a control or $3.125,6.25,8.8$ or $12.5 \mu \mathrm{g}$ DNCB were applied to the right arm and four chambers containing 0.390 , $0.781,1.56$ or $3.125 \mu \mathrm{g}$ DPCP were applied to the left arm. The 

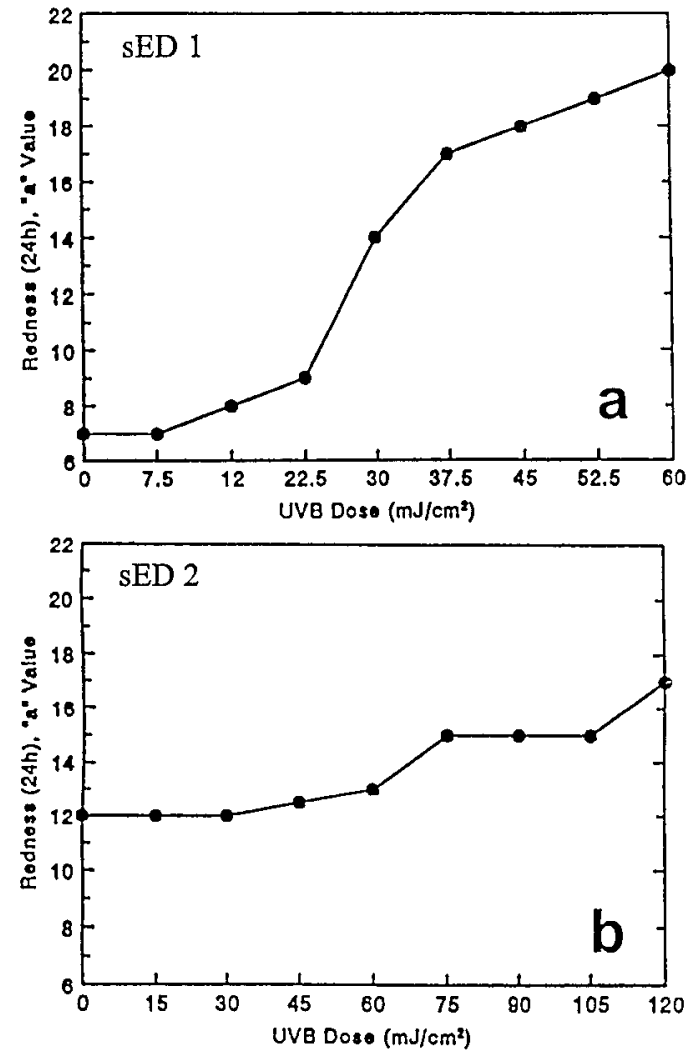

Figure 1. Examples of the erythemal dose response with a steep slope (sED 1) and with a moderate slope (sED 2). The erythemal dose response was assessed using a Minolta Chroma Meter CR-300, where "a" indicates color on an axis from green to red $(60=$ very red, $-60=$ very green). sED $1=\Delta$ in redness at two successive UV doses $\geq 2.0$, sED $2=\Delta$ in redness at two successive UV doses 0.5-2.0.

chambers were left in place for $6 \mathrm{~h}$. An increase in skin fold thickness at the site of challenge was determined using a micrometer with spring-loaded calipers (Mitutoyo Manufacturing, Tokoyo, Japan), by subtracting the measurement before from the measurement $48 \mathrm{~h}$ after the chemical application. A single value which estimates the integral for the entire dose response was recorded as the sum of the increased skin fold thickness at the four DNCB or DPCP challenge sites ( $\Sigma$ edema at four sites).

Statistics. The initial analysis was done using data from 129 subjects summarized in Tables 2 and 3. The data were made more symmetric at each dose level, the variability was made more homogeneous and the response curve was straightened out by logtransformation. Thus a linear dose model could be assumed for the logarithm of the DNCB response. By including additional variables in the model that significantly reduced the variability around the regression line, the estimate of the dose coefficient was improved. To test whether including a given variable would significantly improve the model, a stepwise procedure was used on the following main effects: age, sex (coded zero for females, one for males), MED, baseline pigmentation, logarithm of the DPCP response, sensitization batch number, time and time of year. After the significant main effects were found their interactions and higher powers were also tested (22).

In addition to the above variables there were two grouping variables of interest: the Fitzpatrick skin type groups and the groups determined by the sED. The significance of each grouping was tested separately using the regression model found above. In each case, indicator variables were used to start with a full model that allowed different coefficient values for each group. In the case of the sED grouping the model was used to test which of the sED groups could be combined as a single group without detracting from the model. In the case of the Fitzpatrick grouping the model was examined to see which variables in the original model were not affected by the skin type grouping. Since only one subject was typed as a Fitzpatrick type I, that subject was dropped for this part of the analysis and only the five types, II-VI, were considered.

Finally, the combination of the supplemental study of 56 subjects with the original study group of 129 subjects was considered. Since several of the variables tested for inclusion in the model were not available for this supplemental study, an abbreviated model was used for the combined group to test the significance of the sED grouping.

The relation between the DPCP response and the UVR dose was also examined. The same models of main effects found for the $\ln$ (DNCB response) were reanalyzed by switching the $\ln (\mathrm{DPCP}$ response) and $\ln (\mathrm{DNCB}$ response) terms, thus examining the $\ln (\mathrm{DPCP}$ response) as a function of UVR dose.

\section{RESULTS}

\section{Erythemal responses}

Initially subjects were divided into five skin types based on their MED response (Table 2). When these groups were exposed to a fixed dose of $60 \mathrm{~mJ} / \mathrm{cm}^{2}$, there was a progressive decrease in erythema (assessed by chroma meter) as the MED range increased (Table 2). There was a progressive decrease in the SED with increased MED range, such that for the group with the highest MED range it was difficult to determine an MED. There was also a progressive increase in baseline pigmentation. When subjects were grouped ac-

Table 2. 129 Subjects grouped by skin type based on MED

\begin{tabular}{|c|c|c|c|c|c|c|}
\hline $\begin{array}{c}\text { MED* } \\
\left(\mathrm{mJ} / \mathrm{cm}^{2}\right)\end{array}$ & & $\mathrm{n}(\mathrm{m} / \mathrm{f})$ & $\begin{array}{c}\text { Age (years) } \\
(\text { mean } \pm \text { SE) }\end{array}$ & $\begin{array}{c}\text { Baseline } \\
\text { pigmentation } \dagger\end{array}$ & $\begin{array}{l}\text { Erythema } \\
\text { after } 60 \mathrm{~mJ} / \mathrm{cm}^{2}\end{array}$ & sED§ \\
\hline $30-37.5$ & (I, II, II, IV)\| & $20(13 / 7)$ & $30.7(1.2)$ & $31.7(0.7)$ & $10.1(0.7)$ & $1.0(0.0)$ \\
\hline $45-60$ & (II, III, IV, V) & $45(19 / 26)$ & $30.0(1.2)$ & $35.6(1.0)$ & $5.9(0.4)$ & $1.1(0.1)$ \\
\hline 75 & $(\mathrm{IV}, \mathrm{V})$ & $14(4 / 10)$ & $33.0(2.9)$ & 48.9 (1.6) & $2.3(0.3)$ & $1.7(0.2)$ \\
\hline $90-105$ & $(\mathrm{IV}, \mathrm{V})$ & $16(2 / 14)$ & 31.4 (1.7) & $48.6(1.6)$ & $1.7(0.3)$ & $1.8(0.01)$ \\
\hline$>105$ & $(\mathrm{IV}, \mathrm{V}, \mathrm{VI})$ & $34(20 / 14)$ & 28.9 (1.4) & $59.4(1.2)$ & $0.3(0.1)$ & $2.6(0.1)$ \\
\hline
\end{tabular}

*Minimal erythemal dose (the minimal dose required to produce skin reddening) range; MED refers here to the subject's erythemal response and is not a reference to the dose of UVR administered in the immune suppression studies.

$†$ Chroma meter darkness-lightness scale $(100-$ - "L"); mean \pm SE.

$\ddagger$ Increase in redness by chroma meter $24 \mathrm{~h}$ after $60 \mathrm{~mJ} / \mathrm{cm}^{2}$, mean $\pm \mathrm{SE}$.

§ased on slope of curve obtained from chroma meter readings of erythema at increasing doses of UVR $(1=$ steep; $2=$ moderate; $3=$ flat); values are mean \pm SE

||Roman numerals represent Fitzpatrick skin types contained within this group. 
Table 3. 129 Subjects grouped by ED rate

\begin{tabular}{|c|c|c|c|c|c|}
\hline sED* & $\mathrm{n}(\mathrm{m} / \mathrm{f})$ & $\begin{array}{l}\text { Age (years) } \\
(\text { mean } \pm S E)\end{array}$ & $\begin{array}{c}\text { Baseline } \\
\text { pigmentation } \dagger\end{array}$ & $\begin{array}{c}\text { Erythema } \\
\text { after } 60 \mathrm{~mJ} / \mathrm{cm}^{2} 末\end{array}$ & MED $\mathrm{mJ} / \mathrm{cm}^{2} \S$ \\
\hline 1 (I, II, III, IV, V)\| & $73(32 / 41)$ & $31.3(1.1)$ & $35.0(0.6)$ & $3.0(0.4)$ & $50.0(1.5)$ \\
\hline $2(\mathrm{IV}, \mathrm{V}, \mathrm{VI})$ & $34(17 / 17)$ & $31(1.2)$ & $52.2(0.8)$ & $1.3(0.1)$ & $102.3(3.9)$ \\
\hline $3(\mathrm{~V}, \mathrm{VI})$ & $22(10 / 12)$ & $28(3.8)$ & $61(6.0)$ & $0.04(0.8)$ & 150 \\
\hline
\end{tabular}

*Based on slope of curve obtained from chroma meter readings of erythema at increasing doses of UVR $(1=$ steep; $2=$ moderate; $3=$ flat); values are mean $\pm \mathrm{SE}$.

$\dagger$ Chroma meter darkness-lightness scale (100 - "L"); mean \pm SE.

†Increase in redness by chroma meter $24 \mathrm{~h}$ after $60 \mathrm{~mJ} / \mathrm{cm}^{2}$, mean $\pm \mathrm{SE}$.

$\S$ Mean and standard error of subjects MED responses.

||Roman numerals represent Fitzpatrick skin types contained within this group.

cording to sED (Table 3) progressive increases in these parameters and in the mean MED response were also observed.

\section{Immune suppression dose response based on 129 subjects}

The numbers of subjects in each MED group were not well balanced and the number of subjects per group was relatively
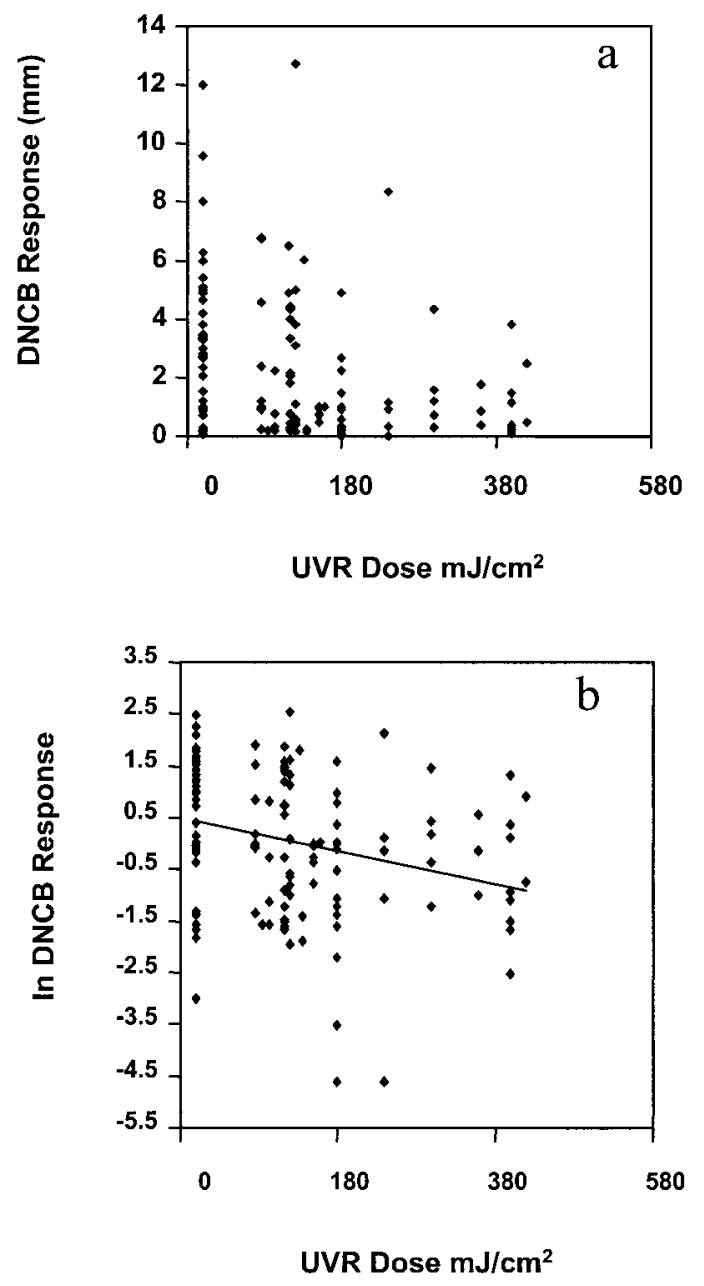

Figure 2. Scatter plot of immune response $v s$ dose of UVB for 129 subjects initially studied. a: The data expressed as difference in skin thickness. $\mathrm{b}$ : $\ln$ transformation of the data. $\mathrm{R}^{2}=0.737$. Coefficient of dose is significant $(P=0.002)$. low. Rather than arbitrarily combining groups to overcome these problems, we began our analysis by considering the entire data set. Figure $2 \mathrm{a}$ plots the immune response to DNCB against the dose $\left(\mathrm{mJ} / \mathrm{cm}^{2}\right)$ of UV and shows that the response diminishes with increasing dose, but the effect seems to level off from 300 to $400 \mathrm{~mJ} / \mathrm{cm}^{2}$, i.e. the response is not linear. Also, the data are more spread out where the response is high (for low UVR doses) than where the response is smaller (for high doses), and the data are skewed on the low side because there are more low responders than high responders at every dose level. Hence, the distributions are asymmetric. These problems are greatly reduced in Fig. $2 \mathrm{~b}$, which plots the logarithm of the immune response against the dose of UVR. Although the slope of the line in Fig. $2 b$ is quite shallow, when the logarithm of the DNCB response was regressed against the UVR dose without any additional covariates, the dose response was seen to be highly significant $(P=0.002)$ but explained only a small part of the variability in the data $\left(\mathrm{R}^{2}=0.0737\right)$, i.e. only $7.37 \%$ of the variability in the data is explained by the UVR dose. Several experimental variables (main effects) were found to explain a significant $(P<0.05)$ amount of the variability in the response to DNCB. These included the sex, age, batch number for the DNCB solution used to sensitize the subjects, the response to DPCP and of course dose. Surprisingly neither of the variables associated with pigmentation (MED or baseline pigmentation) was selected by the stepwise process for inclusion in the regression model, indicating that differences in pigmentation did not significantly affect the response to UVR-induced immune suppression. The analysis of the two grouping variables, sED and the Fitzpatrick skin type classification, also suggested that pigmentation did not have a significant effect on the UVR dose response for immune suppression.

\section{Expanding the dose response to include 185 subjects}

Since the original study population did not include many very fair subjects, supplemental data from 56 fair-skinned subjects assessed in a similar study were added to the data from the study described above. Again, most of the variables associated with pigmentation did not contribute significantly to the variability in the DNCB response. However, in contrast to the earlier analysis, the model that included the 56 fairer subjects (all with $\mathrm{sED}=1$ ) was significantly improved by adding the sED grouping. Combinations of the groups 


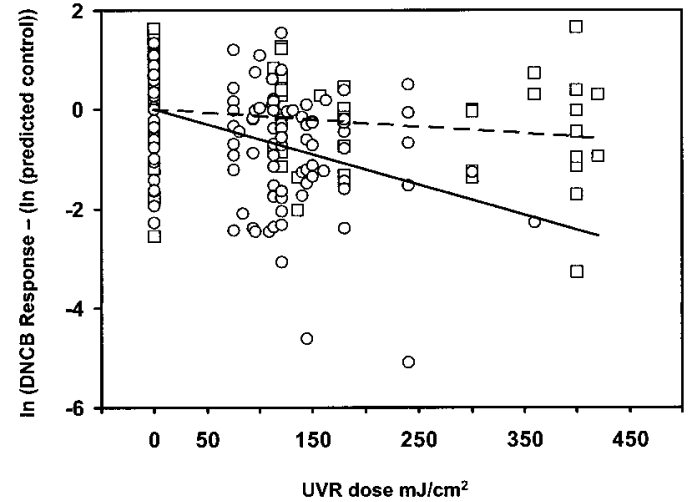

Figure 3. The dose response model using sED as a grouping variable and including 185 subjects from the combined studies. For subjects with sED 1 (circles and solid line) 50\% suppression of the response $=114 \mathrm{~mJ} / \mathrm{cm}^{2}$. Confidence interval $(95 \%)$ is 69 and 170 $\mathrm{mJ} / \mathrm{cm}^{2}$. For subjects with sED $2 / 3$ (squares and broken line) the $50 \%$ suppression dose could not be computed because the dose response was too shallow.

were tested to see if any two of the groups could be combined. No difference was found between the groups with sED 2 and 3, but this combined group was significantly different from the group with sED 1 . The dose responses for subjects with sED 1 and sED 2/3 subjects combined are shown in Fig. 3. The lack of a dose response for the sED 2/ 3 group is obvious. Because the dose coefficient for the combined group with sED 2 or 3 was not significant, a meaningful $50 \%$ immune suppression dose could not be found. In order to compute the $50 \%$ immune suppression doses for the subjects with $\mathrm{sED}=1$, the following model was used:

$$
\begin{aligned}
\ln (\mathrm{DNCB})= & 0.3181+0.2856 \ln (\mathrm{DPCP})-0.7649 \\
& \times \operatorname{sex}+0.0193 \times \text { age }-0.006102 \times \text { dose }
\end{aligned}
$$

where DNCB and DPCP refer to the immune (contact sensitivity) response to each chemical, dose was expressed as $\mathrm{mJ} / \mathrm{cm}^{2}$ and sex was expressed as zero for females and one for males. All the variables associated with the model are significant $(P<0.05)$. The dose of UVR required to suppress the immune response by $50 \%$, derived from this equation, was $113.6 \mathrm{~mJ} / \mathrm{cm}^{2}$ with a $95 \%$ confidence interval $(68.7,170.3)$.

Figure 4 shows the distribution of subjects in the sED 1 and SED 2/3 groups with respect to MED and demonstrates that the SED groups cannot be readily described by an MED range. There is considerable overlap with some of the sED 2/3 subjects having lower MED and some of the sED 1 subjects having higher MED. It should also be noted that sED groups cannot be readily described by Fitzpatrick skin types contained within each group. Forty subjects in the Fitzpatrick IV classification and six in the Fitzpatrick V classification were in the sED 1 group which also contained all the Fitzpatrick I-III subjects. There were six Fitzpatrick IV subjects in the sED 2/3 group which contained all the Fitzpatrick VI subjects and all but six of the Fitzpatrick V subjects.

\section{No distant effect of UVR on immunization to DPCP}

The response to DPCP, the antigen applied to unirradiated skin, was not at all correlated with UVR dose. No significant

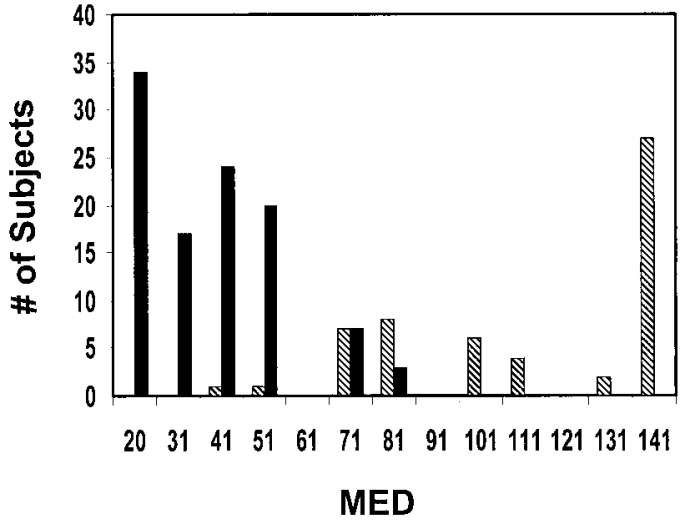

Figure 4. Distribution of subjects in the sED 1 (solid bars) and subjects in the sED 2/3 groups (hatched bars) with respect to MED. Data are from combined studies (185 subjects).

relationship between DPCP response and UVR dose could be established.

\section{DISCUSSION}

The results of this study suggest that pigmentation does not play a major role in the susceptibility to UVR-induced immune suppression in humans. Neither baseline pigmentation nor MED or Fitzpatrick classifications contribute significantly to the dose response. Other investigators have also suggested that melanin does not protect against UVR-induced immune suppression (12). Because the contribution of pigmentation to UVR-induced immune suppression is not great and, as with most human studies, there is a great deal of variability in the response to both UVR and DNCB, dose responses for multiple skin types could not be developed. This is at least, in part, due to the presence of UVR resistant (sED 2/3) subjects across many skin type groups.

In contrast to pigmentation differences in sensitivity could be distinguished between subjects with a steep erythemal dose response curve (sED 1) and those with a moderate or flat erythemal dose response curve (sED 2/3). We suggest that the subjects with sED 2 or 3 were resistant to UVRinduced immune suppression. This group included all of the very dark-skinned subjects for whom an MED response could not be readily calculated; hence, exposure concentrations were not based on MED. Perhaps much higher exposures would have produced both erythemal and immune-suppression dose response curves. In any case this group is clearly much more resistant than the sED 1 group. Although the sED 2/3 group included all of the subjects with MED responses greater than $90 \mathrm{~mJ} / \mathrm{cm}^{2}$, it also included individuals with MED responses as low as $45 \mathrm{~mJ} / \mathrm{cm}^{2}$ and was not limited to the most darkly pigmented subjects. Conversely, our sED 1 group included many IV and some V skin types. The results of this study suggest that the sED provides better information on relative immune responsiveness than the MED representing one point on the erythemal dose response curve. However, the sED was determined using a chroma meter whereas the MED was determined visually. Hence some of the differences between use of MED and SED may simply reflect differences in the methods used to assess erythema. 
The finding that sED identifies the subgroup of human subjects who are immune suppressed by UVB is novel. These results are somewhat in contrast to recent studies in mice which suggest that the molecular mechanisms underlying sunburn and immune suppression are different (23). However, as in our study, Kelly et al. (13) also demonstrated differences in erythemal dose rate for subjects exposed to solar simulated radiation (SSR). Their studies showed that for every $1 \mathrm{~J} / \mathrm{cm}^{2}$ the erythemal response of skin types I/II was significantly greater than for skin types III/IV. Unlike our study their study was limited to Caucasians and their skin type I/II subjects were more sensitive to SSR-induced immune suppression than skin types III/IV. The Kelly study used different methods than we did to assess MED and contact hypersensitivity (CHS) and to analyze the data. They also used a solar simulator rather than the FS-20. Any or all of these differences in the two studies could account for the differences in the results.

Covariates accounted for about $50 \%$ of the variability in the data presented here. Genetic differences in susceptibility may account for a portion of the remaining variability although other factors such as nutritional status might also be involved (24-26). In mice susceptibility to UVR-induced immune suppression appears to be dictated by alleles at polymorphic loci that regulate the production of proinflammatory cytokines (27). Yoshikawa et al. (10) demonstrated that $60 \%$ of normal healthy volunteers were resistant to UVR-induced suppression of contact sensitivity using a protocol similar to that employed in this study. Our SED $2 / 3$ group represents only $30 \%$ of the total number of subjects. We used a much lower dose of DNCB $(30 \mu \mathrm{g})$ than that used in the Yoshikawa study $(2000 \mu \mathrm{g})$. Mouse studies suggest that immunosuppression is likely to be more readily observed with a lower dose of antigen (28). Rather than two distinct populations of UVR resistant and susceptible populations, there may be a more graded response such that the greater the antigenic stimulus, the higher the number of resistant subjects. The potential for greater sensitivity to UVR using a lower dose of antigen is desirable when the goal is to establish a dose response curve to be used in risk assessment. Unfortunately, using a lower concentration of DNCB increases the number of subjects with a very low response to DNCB. This complicated the data analysis. If a large number of subjects were present in the study population that was simply unresponsive to DNCB, our analysis would have underestimated the effect of UVR on the responsive group. However, at higher doses $97.2 \%$ of subjects tested responded to DNCB (10), suggesting that the number of truly unresponsive subjects is likely to be low.

There was no evidence of systemic or distant immune suppression comparable to that seen in mice (29). Suppression of the DPCP response (following sensitization at a site distant from the site of radiation) was not observed. Other investigators failed to detect local UVR-induced immune suppression following sensitization with DPCP at the site of radiation (30), suggesting that DPCP may not be the ideal sensitizer. Others have demonstrated suppression of the systemic response using DNCB (31). The mechanisms associated with systemic suppression in mice (29) appear to exist in humans as well (32-34). Because there is some evidence that the mechanisms responsible for UVR suppression of the delayed-type hypersensitivity response and UVR suppression of contact sensitivity at a distant site are not identical (35), it might be best to pursue further study of systemic effects in humans using a microbial antigen, given that a primary concern associated with systemic suppression is enhanced susceptibility to infectious disease.

The dose responses in this paper are valuable for risk assessment because they are based on physical units (similar to those used in exposure assessments) rather than biological units (MED). In order to understand the impact of depletion of stratospheric ozone on immune responses, risk assessors ideally need action spectrum data on the immunosuppressive effects of UVB at wavelengths most likely to be affected by ozone depletion (295-305 nm) (36). Neither data obtained with an FS-20 sun lamp nor data obtained with a solar simulator (13) provides this information. In a mouse study only about $64 \%$ of the immunosuppressive activity of the FS lamp was attributed to these wavelengths (37). The remaining immunosuppressive activity is attributed to wavelengths below 295 which are unlikely to be affected by currently predicted ozone depletion. Also, we have demonstrated immune suppression in humans exposed to higher UVA-II wavelengths (38). Hence, the predictions in this study may be too conservative. For risk assessment purposes it may be reasonable to make mathematical adjustments based on the action spectrum in mice. A dose response generated with a solar simulator (295-400nm) (13) poses a different problem in that much of the $\mathrm{J} / \mathrm{cm}^{2}$ are generated by wave lengths that are neither immunosuppressive nor affected by ozone. Although such data are useful for predicting risks associated with current solar exposure, exactly how to adjust this dose to predict effects of small increases in $\mathrm{mJ} / \mathrm{cm}^{2}$ at the most immunosuppressive end of the spectrum is unclear.

The only other report of dose response data in humans using an FS lamp indicated that the mixed skin lymphocyte response (MSLR) was suppressed by $50 \%$ at a dose of 420 $\mathrm{mJ} / \mathrm{cm}^{2}$ (39). This number is certainly higher than that of $114 \mathrm{~mJ} / \mathrm{cm}^{2}$ obtained for the sED 1 group in our study, but confidence intervals for the MSLR data were not shown. Therefore, it is unclear how different the two numbers really are. Clearly, the MSLR is a different endpoint although it is presumably related to the contact sensitivity response assessed in our study. The $50 \%$ suppression point computed using our data compares favorably with that reported by Noonan and coworkers $(40,41)$ for systemic and local suppression of contact sensitivity in highly sensitive strains of mice (ranging from 70 to $230 \mathrm{~mJ} / \mathrm{cm}^{2}$ ). It also compares favorable with data reported by Jeevan and Kripke (6) for suppression of the delayed-type hypersensitivity response to mycobacterium bovis bacillus Calmette-Guerin (BCG) (270 $\mathrm{mJ} / \mathrm{cm}^{2}$ ) in more resistant $\mathrm{BALB} / \mathrm{c}$ mice and with values reported for suppression of local contact sensitivity responses in $\mathrm{C} 3 \mathrm{H} / \mathrm{HeNCr}$ mice, but it is lower than that reported to suppress DTH and systemic CHS responses in the same study (35). All of the above studies were conducted using FS lamps. More recently Kelly et al. (13) provided human erythemal and immune suppression dose response data using a solar simulator. Because much of the energy in their source came from higher wavelengths direct comparison between our study and theirs is difficult. The dose computed to suppress the local contact sensitivity response in our sED 1 
subjects is environmentally relevant; $114 \mathrm{~mJ} / \mathrm{cm}^{2}$ could be encountered upon exposure to $1-2 \mathrm{~h}$ of midday summer sun in the central US. Such exposures could have an impact on the effectiveness of vaccines administered through the skin and susceptibility to arthropod borne infections. These latter possibilities deserve further study.

Acknowledgements - This work was funded by EPA Cooperative Agreement CR816177 and CR820510 and Contract 6D1318NTSA.

\section{REFERENCES}

1. Kripke, M. L., J. D. Lofgreen, J. Beard, J. M. Jessup and M. S. Fisher (1977) In vivo immune responses of mice during carcinogenesis by ultraviolet irradiation. J. Natl. Cancer Inst. 59, 1227-1230.

2. Daynes, R. A., C. W. Spellman, J. G. Woodward and D. A. Steward (1977) Studies into the transplantation biology of ultraviolet light-induced tumors. Transplantation 23, 343-348.

3. Noonan, F. P., E. C. De Faba and M. L. Kripke (1981) Suppression of contact hypersensitivity by UV radiation and its relationship to UV-induced suppression of tumor immunity. Photochem. Photobiol. 34, 683-689.

4. Elmets, C. A., P. R. Bergstresser, R. E. Tigelaar, P. J. Wood and J. W. Streilein (1983) Analysis of the mechanism of unresponsiveness produced by haptens painted on skin exposed to low dose ultraviolet radiation. J. Exp. Med. 15, 781-794.

5. Giannini, S. H. (1992) Effects of ultraviolet B irradiation on cutaneous leishmaniasis. Parasitol. Today 8, 44-48.

6. Jeevan, A. and M. L. Kripke (1990) Alteration of the immune response to Mycobacterium bovis BCG in mice exposed chonically to low doses of UV radiation. Cell. Immunol. 13, 32-41.

7. Jeevan, A., K. Gilliam, H. Heard and M. L. Kripke (1992) Effects of ultraviolet radiation on the pathogenesis of Mycobacterium lepraemurium infection in mice. Exp. Dermatol. 1, 152160.

8. Norval, M., A. el-Ghorr, J. Garssem and H. Van Loveren (1994) The effects pf ultraviolet irradiation on viral infections. Br. J. Dermatol. 130, 693-700.

9. Brown, E. L., J. M. Rivas, S. E Ullrich, C. R. Young, S. J. Norris and M. L. Kripke (1995) Modulation of immunity to Borrelia burgdorferi by ultraviolet irradiation: Differential effects on Th1 and Th2-type immune responses. Eur. J. Immunol. 25, 3017-3022.

10. Yoshikawa, T., V. Rae, W. Bruins-Slot, J.-W. Van den Berg, J. R. Taylor Jr. and J. W. Streilein (1990) Susceptibility to effects of UVB radiation on induction of contact hypersensitivity as a risk factor for skin cancer in humans. J. Investig. Dermatol. 95, 530-536.

11. Cooper, K. D., B. S. Oberhelman, M. S. Hamilton, O. Baadsgaard, M. Terhune, G. LeVee, T. Anderson and H. Koren (1992) UV exposure reduces immunization rates and promotes tolerance to epicutaneous antigens in humans; relationship to dose, $\mathrm{CD} 1 \mathrm{a}^{-} \mathrm{DR}^{+}$epidermal macrophage induction and Langerhans cell depletion. Proc. Natl. Acad. Sci. 89, 8497-8501.

12. Vermeer, M., G. J. Schmieder, T. Yoshikawa, J.-W. Van den Berg, M. S. Metzman, J. R. Taylor and J. W. Streilein (1991) Effects of ultraviolet B light on cutaneous immune responses of humans with deeply pigmented skin. J. Investig. Dermatol. 97, 729-734.

13. Kelly, D. A., A. R. Young, J. M. McGregor, P. T. Seed, C. S. Potten and S. L. Walker (2000) Sensitivity to sunburn is associated with susceptibility to ultraviolet radiation-induced suppression of cutaneous cell-mediated immunity. J. Exp. Med. 191, 561-566.

14. Selgrade, M. J. K., M. H. Repacholi and H. S. Koren (1997) Meeting report: ultraviolet radiation-induced immune modulation: potential consequences for infectious, allergic, and autoimmune disease. Environ. Health Perspect. 105, 2-4.

15. Noonan, F. P., M. L. Kripke, G. M. Pedersen and M. I. Green (1990) Suppression of contact hypersensitivity in mice by ultraviolet irradiation is associated with defective antigen presentation. Immunology 43, 527-533.
16. Howie, S., M. Norval and J. Maingay (1986) Exposure to lowdose ultraviolet radiation suppresses delayed-type hypersensitivity to Herpes Simplex virus in mice. J. Investig. Dermatol. 86, $125-128$.

17. Streilein, J. W., J. R. Taylor, V. Vincek, I. Kurimoto, T. Shimizu, C. Tie and C. Golomb (1994) Immune surveillance and sunlight-induced skin cancer. Immunol. Today 15, 174-179.

18. Scotto, J., T. R. Fears and J. F. Fraumeni (1983) Incidence of nonmelanoma skin cancer in the United States. National Cancer Institute, Bethesda (NIH publication no. 83-2433).

19. Fitzpatrick, T. B. (1988) The validity and practicality of sunreactive skin types I through VI. Arch. Dermatol. 124, 869-871.

20. Rhodes, A. R., M. A. Weinstock, T. B. Fitzpatrick, M. C. Mihm and A. J. Sober (1987) Risk factors for cutaneous melanoma. A practical method of recognizing predisposed individuals. J. Am. Med. Assoc. 25, 3146.

21. Oberhelman, L., H. Koren and K. D. Cooper (1992) Depressed capacity to contact sensitize women at the onset of menses; elevated contact sensitization capacity during mid cycle can be inhibited by UV. J. Investig. Dermatol. 98, 655.

22. Kleinbaum, D. G., L. L. Kupper and K. E. Muller (1988) Applied Regression Analysis and Other Multivariable Methods. PWS-KENT, Boston.

23. Garssen, J., H. van Steeg, F. de Gruijl, J. de Boer, G. T. J. van der Horst, H. van Kranen, H. van Loveren, M. van Dijk, A. Fluitman, G. Weeda and J. H. J. Hoeijmakers (2000) Transcription-coupled and global genome repair differentially influence UV-B-induced acute skin effects and systemic immunosuppression. J. Immunol. 164, 6199-6205.

24. Fuller, C. J., H. Faulkner, A. Bendich, R. S. Parker and D. A. Roe (1992) Effect of $\beta$-carotene supplementation on photosuppression of delayed-type hypersensitivity in normal young men. Am. J. Clin. Nutr. 56, 684-690.

25. Black, H. S., G. Okotie-Eboh, J. Gerguis, J. I. Urban and J. I. Thornby (1995) Dietary fat modulates immunoresponsiveness in UV-irradiated mice. Photochem. Photobiol. 62, 964-969.

26. Steerenberg, P. A., J. Garssen, P. Dortant, P. C. Hollman, G. M. Alink, M. Dekker, H. B. Bueno-de-Mesquita and H. Van Loveren (1998) Protection of UV-induced suppression of skin contact hypersensitivity: a common feature of flavonoids after oral administration. Photochem. Photobiol. 67, 456-461.

27. Yoshikawa, T. and J. W. Streilein (1990) Genetic basis of the effects of ultraviolet light B on cutaneous immunity. Evidence that polymorphism at the Tnf $\alpha$ and Lps loci governs susceptibility. Immunogenetics 32, 398-405.

28. Yamawaki, M., S. K. Katiyra, C. Y. Anderson, K. A. Tubesing, H. Mukhtar and C. A. Elmets (1997) Genetic variation in lowdose UV-induced suppression of contact hypersensitivity and in the skin photocarcinogenesis response. J. Investig. Dermatol. 109, 716-721.

29. Ullrich, S. E. (1998) The effect of UV exposure on the activation of T-cell subsets. In T Lymphocyte Subpopulations in Immunotoxicology (Edited by I. Kimber and M. J. K. Selgrade), pp. 121-142. Wiley, New York.

30. Friedli, A., T. Hunziker, B. Finkel and L. R. Braathen (1993) Effects of acute, low-dose UVB radiation on the induction of contact hypersensitivity to diphenylcyclopropenone in man. Arch. Dermatol. Res. 285, 1-5.

31. Kelly, D. A., S. L. Walker, J. M. McGregor and A. R. Young (1998) A single exposure of solar simulated radiation suppresses contact hypersensitivity responses both locally and systemically in humans: quantitative studies with high-frequency ultrasound. J. Photochem. Photobiol. B: Biol. 44, 130-142.

32. Kang, K., C. Hammerberg, L. Neunier and K. D. Cooper (1994) $\mathrm{CD} 11 \mathrm{~b}+$ macrophages that infiltrate human epidermis after in vivo ultraviolet exposure potently produce IL-10 and represent the major secretory source of epidermal IL-10 protein. J. Immunol. 153, 5256-5264.

33. Kang, K., A. C. Gilliam, G. Chen, E. Tootell and K. D. Cooper (1998) In human skin UVB initiates early induction of IL-10 over IL-12 preferentially in the expanding dermal monocytic/ macrophagic population. J. Investig. Dermatol. 11, 31-38.

34. Yoshida, Y., K. Kang, M. Berger, G. Chen, A. C. Gilliam, A. Moser, L. Wu, C. Hammerberg and K. D. Cooper (1998) Mono- 
cyte induction of IL-10 and down-regulation of IL-12 by iC3b deposited in ultraviolet-exposed human skin. J. Immunol. 16, 5873-5879.

35. Kim, T. H., S. E. Ullrich, H. N. Ananthaswamy, S. Zimmerman and M. L. Kripke (1998) Suppression of delayed and contact hypersensitivity responses in mice have different UV dose responses. Photochem. Photobiol. 68, 738-744.

36. Lenoble, J. (1993) Atmospheric Radiative Transfer. Deepak Publishing, Hampton.

37. Learn, D. B., D. G. Beasley, L. D. Giddens, J. Beard, J. W. Stanfield and L. K. Roberts (1995) Minimum doses of ultraviolet radiation required to induce murine skin edema and immunosuppression are different and depend on the ultraviolet emission spectrum of the source. Photochem. Photobiol. 62 , 1066-1075.
38. LeVee, G. J., L. Oberhelman, T. Anderson, J. Koren and K. D. Cooper (1996) UVA II exposure of human skin results in decreased immunization capacity, increased induction of tolerance and unique pattern of epidermal antigen-presenting cell alteration. Photochem. Photobiol. 65, 622-629.

39. Goettsch, W., J. Garssen, W. Slob, F. R. Gruijl and H. Van Loveren (1998) Risk assessment for the harmful effects of UVB radiation on the immunological resistance to infectious diseases. Environ. Health Perspect. 106, 71-77.

40. Noonan, F. P. and H. A. Hoffman (1994) Susceptibility to immunosuppression by ultraviolet B radiation in the mouse. Immunogenetics 39, 29-39.

41. Noonan, F. P. and E. C. De Fabo (1990) Ultraviolet-B doseresponse curves for local and systemic immunosuppression are identical. Photochem. Photobiol. 52, 801-810. 